\title{
Soil Type Influence on the Adsorption of Glyphosate in the "Office Du Niger" Zone in Mali
}

\author{
B. Traoré ${ }^{1 *}$, B. B. Traoré ${ }^{1}$, M. Badiaga ${ }^{1}$, S.Dambé ${ }^{2}$, A. Diallo ${ }^{2}$, S.Traorée ${ }^{2}$, D. Samaké ${ }^{1}$, S.S. \\ Guindo $^{2}$, M. Plea ${ }^{2}$, F. Elsass ${ }^{3}$, J. Duplay ${ }^{3}$, M. Millet ${ }^{3}$ \\ ${ }^{1}$ Institute of Applied Sciences, University of Sciences, Technics and Technologies of Bamako-Mali \\ ${ }^{2}$ Faculty of Sciences and Technics, University of Sciences, Technics and Technologies of Bamako - Mali \\ ${ }^{3}$ Laboratory of materials, surfaces and processes for catalysis, University of Strasbourg, France
}

*Corresponding Authors: Boubacar Traoré, Department of Applied Chemistry of Institute of Applied Sciences (ISA) -University of Sciences, Technics and Technologies of Bamako-Mali,

\begin{abstract}
Mali, whose dominant sector of the economy is agriculture, uses large quantities of fertilizers and pesticides to increase yields and ensure measured crop protection. The increasing misuse of these inputs has led to soil and water pollution in these areas [4].
\end{abstract}

While pesticides have helped increase crop yields by controlling pests, their environmental impact remains a major problem.

The objective of this work is to study the natural mechanism of elimination of used pesticides by the interaction of soils with them in terms of adsorption.

The study consisted in exploring the adsorption possibilities of the most widely used herbicide in Mali: glyphosate. For this purpose, three types of soil were characterized. Thus, for the characterization, laser granulometry, X-ray diffraction, atomic emission by plasma torch, high pressure liquid chromatography were used.

The $\mathrm{SiO}_{2} / \mathrm{Al}_{2} \mathrm{O}_{3}$ ratios of Moursi 1.54, Dian 1.55 and Danga 1.92 are close to 2, showing that there is certainly kaolinite but possibly smectites (or free silica). This is consistent with the 2/1 clay types, because of the many substitutions, the $\mathrm{SiO}_{2}: \mathrm{Al}_{2} \mathrm{O}_{3}$ ratio values are generally between 2 and 4 [9]. The results show that the Dian soil is sandy - silty, Danga silty - sandy and Moursi silty. The specific surface areas of the soil samples are $61.5 \mathrm{~m}^{2} \cdot \mathrm{g}^{-1}$ for Danga, $98.8 \mathrm{~m}^{2} . \mathrm{g}^{-1}$ for Dian and $97.2 \mathrm{~m}^{2} . \mathrm{g}^{-1}$ for Moursi.

Adsorption experiments show that glyphosate is better adsorbed on the soils studied because of their differences in solubility and their respective structures. The adsorption of glyphosate follows the Freundlich model, with low $K_{f}$ coefficients indicating its greater affinity for the liquid phase. However, in soils, its adsorption is more favorable on Dian and Moursi than on Danga, due in part to the clay and organic matter content and the specific surface area of the clays.

Keywords: Mali; soil; adsorption; glyphosate.

\section{INTRODUCTION}

Agriculture occupies an important place in Mali's economy. It represents on average $42 \%$ of the Gross Domestic Product (GDP). However, crops are often confronted with locust invasions and other no less important pests. For crop treatment, the quantities of pesticides used in Mali are estimated at about 5400 tons, i.e. an estimated market value of CFA F 17 billion [1] Agriculture accounts for $90 \%$ of all pesticides used in Mali.

Numerous studies are currently being conducted on the impact of these pesticides in the soil and the treatment of induced pollution [2].

The pollution of the Bafing (tributary of Niger), attested by the presence of pesticide residues in the water of cotton production zones, has been reported since 1994 by Coulibaly and Derlon. [3]

A recent study conducted by Berthé (2007) [4], also noted the presence of pesticide residues in the soil and water of four cotton-growing areas in Mali. 
A report presented by ODI SAHEL (NGO in Mali) on the village irrigated perimeter (PIV) showed that rice farmers now rely more on herbicides than on plowing for field monitoring. In this zone, they rely rather on Round up (about 90\% of farmers in the zone) to control weeds [5].

Pesticides have certainly contributed to increasing crop yields by controlling pests in particular. However, their environmental impact remains a major problem. To address this issue, many techniques for removing pesticides from soils are used, such as: chemical oxidation with ozone; peroxide and permanganate; phytoremediation; in situ Bioaugmentation; ex-situ soil washing; hightemperature technical desorption; Bioreaction; and incineration [6].

All these disposal techniques are very expensive and therefore constitute a major problem for our countries.

Furthermore, whatever the type of soil, the quantities of pesticide remain the same, thus often generating large excesses of products that are dangerous for the soil and surface and ground waters. This is why we think it is better to prevent by avoiding using an excess of pesticide into the environment through a better knowledge of soils and their interactions with the pesticides to be applied.

The aim of this work is to study the natural mechanism of pesticides elimination by the interaction of soils with them in terms of adsorption.

Therefore, our approach consisted in a detailed analysis of the soils in the area, a laboratory study of the adsorption of pesticides on clay minerals in order to adjust the quantities of pesticide to be used according to its adsorption by the said soils.

\section{MATERIAL AND MethodS}

The Office du Niger in Mali is an irrigated area located on the left bank of the Niger River, in the inland delta, about $30 \mathrm{~km}$ downstream from Ségou and $250 \mathrm{~km}$ downstream from Bamako (see map in Figure 1).

The irrigated perimeters represent about 100,000 ha presently. The main activities are, rice-growing, market gardening, sugarcane growing and livestock products production.

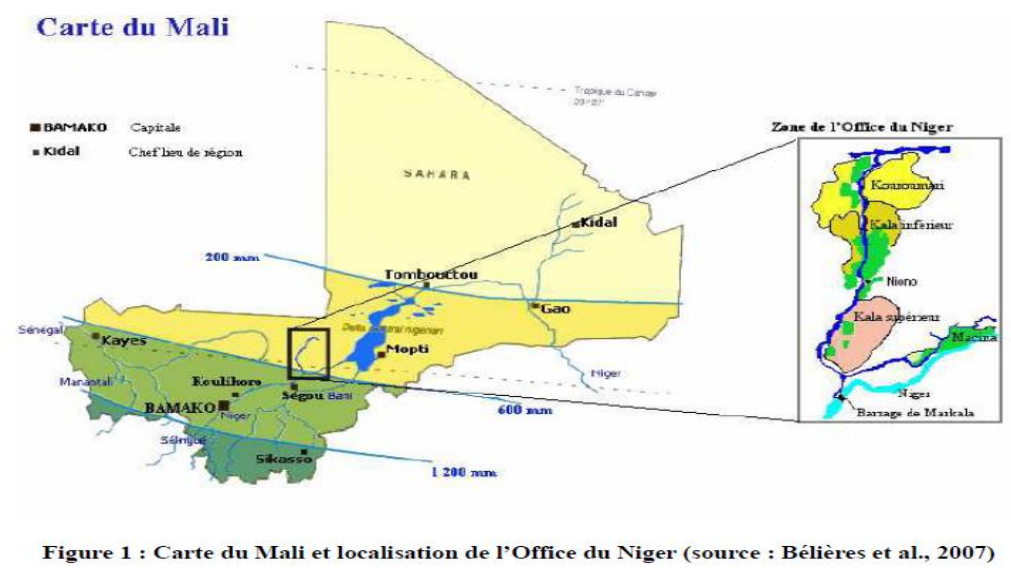

The soil types used are Dian, Danga and Moursi.

Samples were taken at a depth of $20 \mathrm{~cm}$.

The Methods used for the characterization of clay soils are as follows:

- ICP-AES Plasma emission spectrometry for determining the chemical composition of samples.

- The X-Rays Diffraction is measured, using a BRÜKER X-ray diffractometer (model D5000), in $\theta / 2$ $\theta$ mode (Angular scan from 3 to $65^{\circ}, 0.02^{\circ}$ steps of $2 \mathrm{~s}$ duration, Cu-cathode resistant, $40 \mathrm{kV}-30 \mathrm{~mA}$ ).

- Fourier Transformed Infrared (FTIR) of "Perkin-Elmer Fourier Transform 1720-x" brand, over a range of 400 to $4000 \mathrm{~cm}^{-1}$ with a resolution of $2 \mathrm{~cm}$ - helped characterize the different types of clays according to the vibrations of the different functional groups $\mathrm{OH}, \mathrm{H}-\mathrm{OH}, \mathrm{Al}-\mathrm{OH}$ and $\mathrm{Si}-\mathrm{O}$ bonds.

The samples were conditioned as a dispersion in a $\mathrm{KBr}$ pellet (1/200 by weight). 
- The BET method (Brunauer, Emett and Teller) was used to estimate the specific surface area of the clays. The cobaltihexammine ion exchange method was used to determinate the CEC. (see standard NFX31-130 for a complete description of the method).

The studied pesticide is glyphosate, the most widely used herbicide in the world. [8]. It is a member of the organophosphate family. The glyphosate molecule is a non-planar zigzag chain, which has an amine group, a phosphoric acid group and a carboxylic acid group. Its structural formula is as follows.

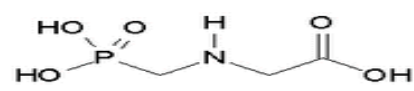

The adsorption procedure consists of dispersing a mass of $15 \mathrm{mg}$ of clay in a $50 \mathrm{~mL}$ pesticide solution of variable concentration $\mathrm{Ci}(0,10,20,30,40,50 \mathrm{mg} / \mathrm{L})$ by mechanical agitation at $28^{\circ} \mathrm{C}$ at $150 \mathrm{rpm}$ for 24 hours.

After centrifugation, the supernatant is analyzed by HPLC. The determinations are carried out with a chromatographic chain consisting of a Hitachi 655A-12 pump, a Gilson 234 autoinjector autosampler equipped with a 20 injection loop $\mu \mathrm{L}$, a RP18 column $(25 \mathrm{~cm}$, with spherical balls of diameter $5 \mu \mathrm{m}$ in octadecyl grafted silica), a Hitachi D-2000 integrator and a Hitachi L-4000 UV detector (set on the maximum UV absorption of the compound used).

The eluent phase - Acetonitile/Water ( $80 / 20$ by volume) is pre-filtered and degassed prior to use. The pump flow rate is $0.5 \mathrm{ml} . \mathrm{mn}^{-1}$.

The quantity of adsorbed product expressed in $\mu$ moles, $\mu \mathrm{g}$ or $\mathrm{mg}$ of solute per gram of adsorbent solid is given by the following relationship: $Q=\frac{\left(C_{0}-C_{e}\right) * V}{m}$

\section{RESULTS AND DISCUSSION}

The various physico-chemical and spectroscopic techniques used helped determine the composition, texture and structure of the three soils studied.

The fine fraction of the Danga, Dian and Moursi soil samples was analysed by X-ray diffraction. Figures 2, 3, 4 show the diffractograms of this analysis.

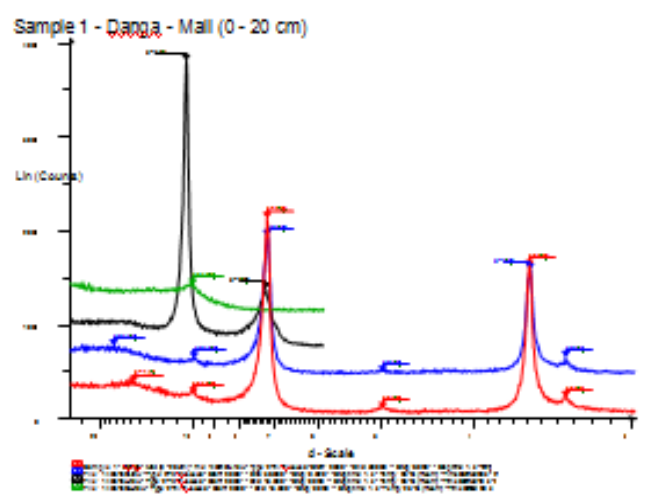

Figure 2: DRX diagram of the $<2 \mu \mathrm{m}$ fraction of Danga

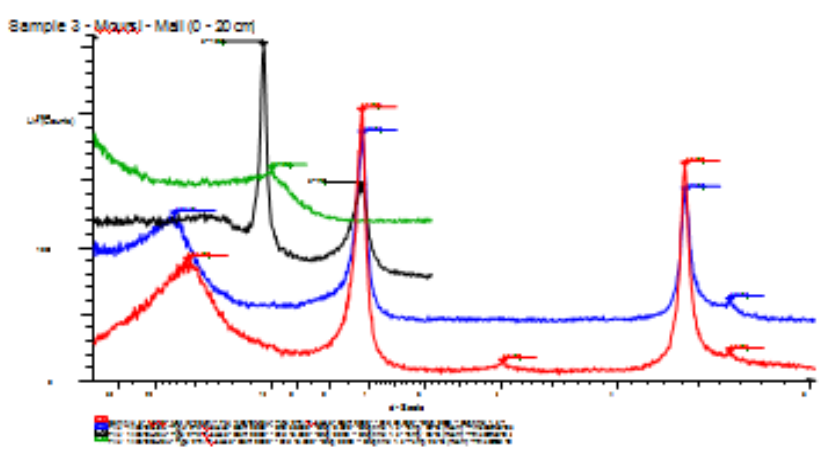

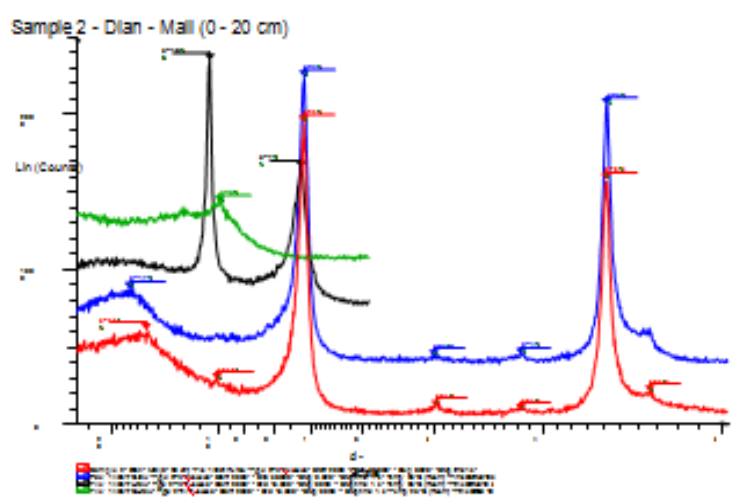

Figure 3: DRX diagram of the $<2 \mu \mathrm{m}$ fraction of Dian

Figure 4: DRX diagram of the $<2 \mu \mathrm{m}$ fraction of Moursi 
The three types of soil contain quartz, feldspath and clay minerals, which are kaolinite, montmorillonite and illite according to the DRX. Semi-quantitative estimates by DRX show that the Moursi fine fraction contains $43.3 \%$ kaolinite and 56.7\% smectite; the Dian fine fraction contains 69.4\% kaolinite and 30.6\% smectite; the Danga fine fraction contains $83 \%$ kaolinite; $15.7 \%$ smectite and $1.3 \%$ illite.

Table1. Chemical composition of the fine fraction expressed as mass percentage of oxide.

\begin{tabular}{|l|l|l|l|l|l|l|l|l|l|l|l|}
\hline Scales & $\mathbf{S i O}_{\mathbf{2}}$ & $\mathbf{A l}_{\mathbf{2}} \mathbf{O}_{\mathbf{3}}$ & $\mathbf{M g O}$ & $\mathbf{C a O}$ & $\mathbf{F e}_{2} \mathbf{O}_{\mathbf{3}}$ & $\mathbf{M n O}$ & $\mathbf{T i O}_{2}$ & $\mathbf{N a}_{\mathbf{2}} \mathbf{O}$ & $\mathbf{K}_{2} \mathbf{O}$ & $\mathbf{P}_{2} \mathbf{O}_{\mathbf{5}}$ & $\mathbf{S i O}_{2} / \mathbf{A l}_{\mathbf{2}} \mathbf{O}_{\mathbf{3}}$ \\
\hline Danga & 48 & 25.0 & 0.48 & 0.7 & 5.26 & 0.02 & 1.20 & 0.10 & 0.8 & 0.1 & 1.92 \\
\hline Dian & 42 & 27.0 & 0.70 & 0.9 & 8.14 & 0.05 & 0.98 & 0.13 & 0.6 & - & 1.55 \\
\hline Moursi & 43 & 27.9 & 0.89 & 1.1 & 6.98 & 0.04 & 0.98 & 0.17 & 0.6 & - & 1.54 \\
\hline
\end{tabular}

The results obtained from the chemical analysis of the fine fraction are expressed as a mass percentage of oxide for each sample. The chemical analysis shows that the clay minerals are mostly kaolinite with $\mathrm{SiO}_{2} / \mathrm{Al}_{2} \mathrm{O}_{3}$ greater than 1.18.

The $\mathrm{SiO}_{2} / \mathrm{Al}_{2} \mathrm{O}_{3}$ ratios of Moursi 1.54, Dian 1.55 and Danga 1.92 are close to 2, which shows that there is certainly kaolinite but perhaps smectites (or free silica). This is consistent with the $2 / 1$ clay types, because of the many substitutions, the $\mathrm{SiO}_{2} / \mathrm{Al}_{2} \mathrm{O}_{3}$ ratio values are generally between 2 and 4 [9].

Iron oxide contents (5-8\%) show their abundance in clay minerals and/or as free oxide such as goethite in Dian.

The relatively high magnesium oxide $\mathrm{MgO}$ grades $(0.48 ; 0.70 ; 0.89)$ in Danga, Dian and Moursi samples, indicate the presence of smectite. Significant amounts of potassium (0.6-0.8) remain, which is consistent with the presence of illite and feldspar.

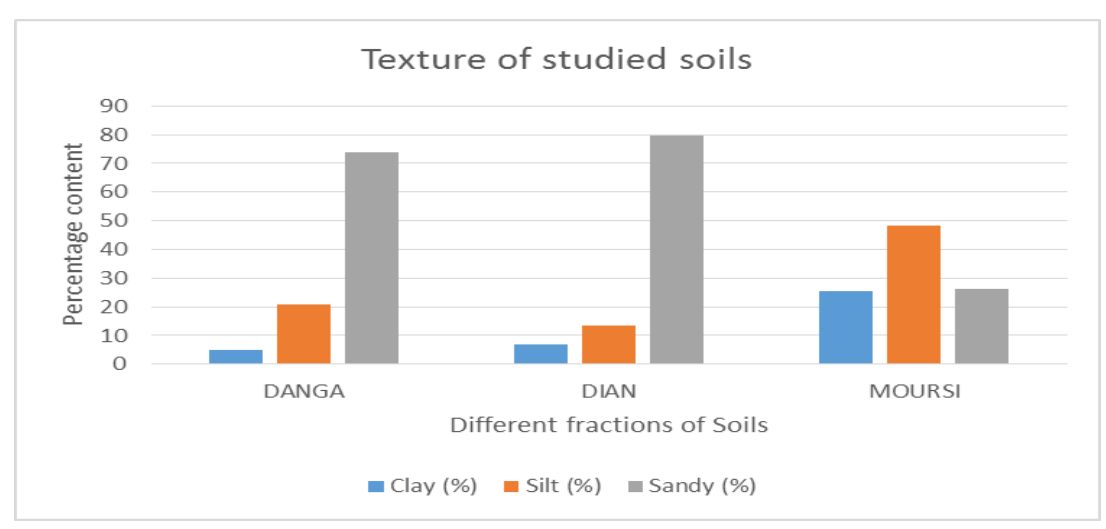

Figure5. Graphical representation of soil texture

The characterization of clay soils showed three types of soils: silty for Moursi, silty-sandy for Danga and sandy-silty for Dian.

Table2. Other physico-chemical characteristics of soils

\begin{tabular}{|l|l|l|l|}
\hline & DANGA & DIAN & MOURSI \\
\hline $\mathrm{pH}$ & 8.00 & 6.54 & 7.50 \\
\hline $\mathrm{S} . \mathrm{s}(\mathrm{m} 2 / \mathrm{g})$ & 61.48 & 98.78 & 97.15 \\
\hline $\mathrm{M} . \mathrm{O}$ & 1.90 & 3.81 & 6.03 \\
\hline C.E.C(g/100g) & 19.6 & 27.20 & 36.6 \\
\hline Phases of $7 \AA$ & 83 & 69.4 & 43.3 \\
\hline Phases of $10 \AA$ & 1.3 & 0 & 0 \\
\hline Phases of $15 \AA$ & 15.7 & 30.6 & 56.7 \\
\hline
\end{tabular}

Table 2 shows the results of the other physico-chemical analyzes carried out on the three soil types.

The specific surface areas of the soil samples were measured by the B.E.T. method with nitrogen at $77 \mathrm{~K}$. They are $61.5 \mathrm{~m}^{2} . \mathrm{g}^{-1}$ for Danga, $98.8 \mathrm{~m}^{2} . \mathrm{g}^{-1}$ for Dian and $97.2 \mathrm{~m}^{2} . \mathrm{g}^{-1}$ for Moursi.

These values are relatively high compared to those obtained for kaolite/humic acid clay/humic acid complexes $\left(13 \mathrm{~m}^{2} \cdot \mathrm{g}^{-1}\right)$, for silica $\left(6 \mathrm{~m}^{2} \cdot \mathrm{g}^{-1}\right)$ or for other soil samples $\left(20.8 \mathrm{~m}^{2} \cdot \mathrm{g}^{-1}\right)$. They are very low 
compared to those for clay alone (10 to $30 \mathrm{~m}^{2} \cdot \mathrm{g}^{-1}$ for kaolinite and chlorite, 100 to 175 for illite and 700 to 800 for montmorillonite).[10]

The organic matter content of the Moursi samples is higher than the others. The same is true for the clay percentages. This explains the relatively high specific surface area values of this same sample compared to the others.

\section{Glyphosate adsorption isotherms on pure clays.}

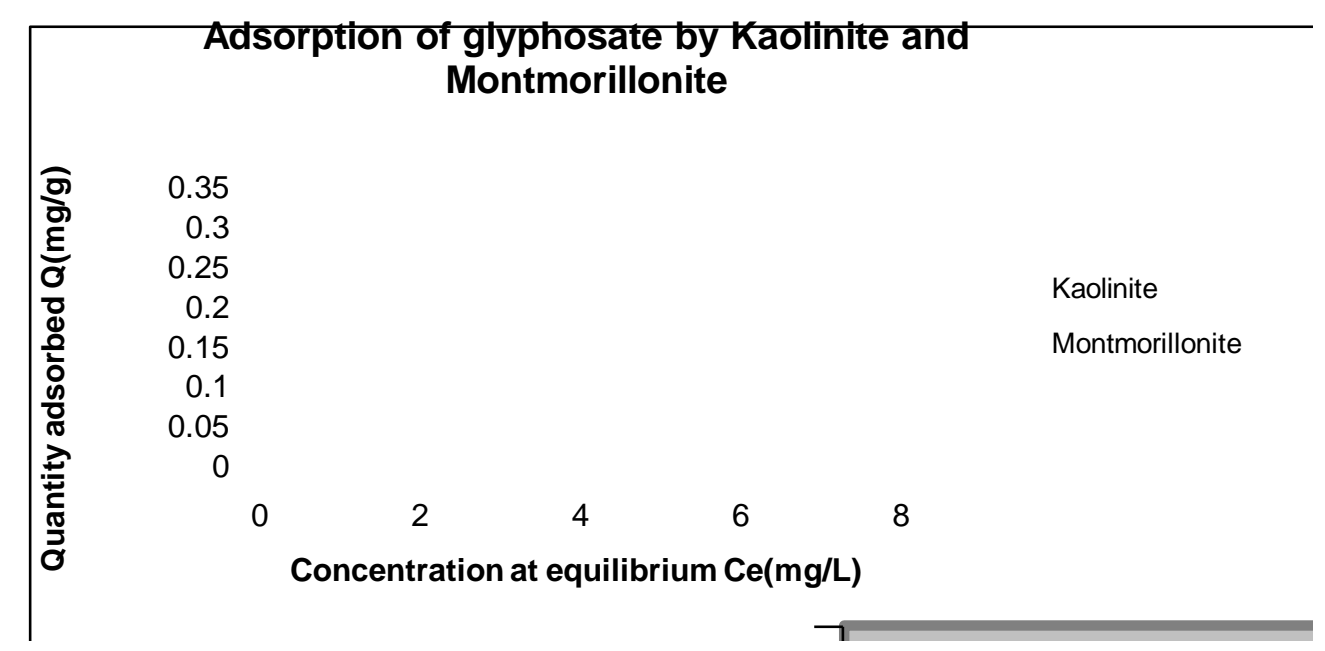

Figure6. Glyphosate adsorption isotherm by Kaolinite and Montmorillonite

Non-swelling clay kaolinite, whose interlayer space does not normally participate in adsorption, has a better retention capacity for the pesticide. It quickly reaches high adsorbed quantities at the lowest equilibrium concentrations (Ce concentrations below $1.5 \mathrm{mg} / \mathrm{L}$ ). Though smectite has a slow adsorption capacity or even low compared to that of kaolinite, its exchange capacity at the interleaf surfaces is high.

Exchanges at the leaf level seem to be little responsible for the retention of pesticide molecules. This means that the latter are rather fixed by electrostatic adsorption on other sites such as the clusters located on the edges of the leaflets.

These results are in line with the work carried out by Emna errais 2011 [11] which found that Kaolinite had a better retention capacity than montmorillonite on dyestuffs. Also, Toraishi et al.2002 [12], You et al.2001 [13] reported the unsuccessful exchange of carbonate anions in the interleaf space by phosphate, silicate and iodate anions.

In browsing through the chemical compositions, it can be seen that kaolinite from the state of Georgia has relatively large amounts of $\mathrm{TiO}_{2}$ and $\mathrm{Fe}_{2} \mathrm{O}$ and mineralogical analysis shows the presence of impurities such as quartz and anatase $(0.354 \%)$. Source clays Repository, the clays Minerals

However, some authors (Barja, 1999 [14]; Barja and Afonso dos Santos ,2005) [15] have shown that the phosphonate group is responsible for the strong adsorption of glyphosate on iron oxides and also for the complexation of free metals in aqueous solution [16]; [17] and therefore kaolinite would adsorb more than montmorillonite.

\section{Glyphosate adsorption isotherms on clay soils}

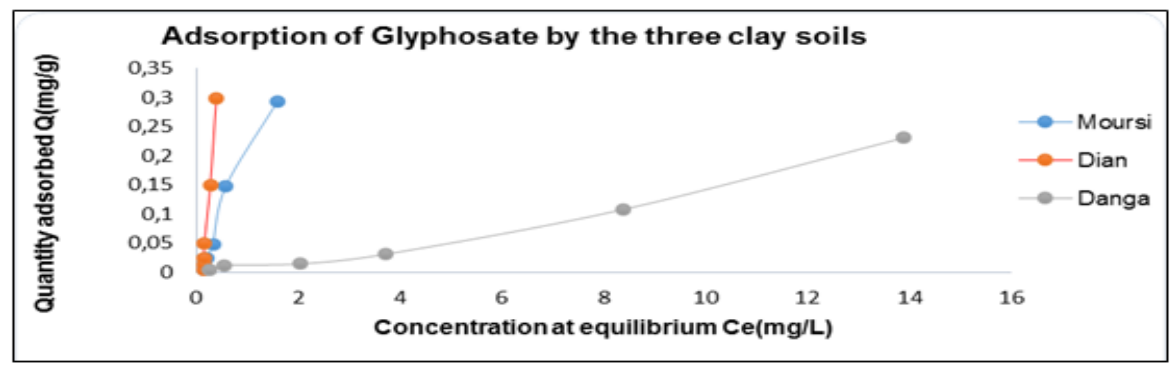

Figure7. Glyphosate adsorption isotherms on different clay soils 
The three isothermal curves show more or less marked differences, depending on the nature of the clay.

The difference is significant between Danga and the other two. Dian quickly reaches a high adsorption rate of $0.3 \mathrm{mg} / \mathrm{g}$ at low equilibrium concentrations of around $2 \mathrm{mg} / \mathrm{L}$ followed by Moursi. These two curves are broadly similar. It can be said that they have the same behavior with respect to glyphosate. As for Danga, it reaches its maximum at $0.25 \mathrm{mg} / \mathrm{g}$ with a concentration of $15 \mathrm{mg} / \mathrm{L}$. Adsorption is therefore slow with this clay.

Two stages can be identified by looking at the curve:

- the first stage is characterized by a weak adsorption where the herbicide is probably retained by electrostatic forces

- the second step which is characterized by a large variation in adsorption shows that the matrix becomes increasingly hydrophobic and involves strong interactions between both adsorbent and adsorbate.

Globally, the order of glyphosate reactivity on the three types of clay soils is as follows: Danga< Moursi< Dian

These results are in agreement with those of Armand and Jacobsen (2001) [8] who find that the adsorption of glyphosate is ensured in particular by clays and organic compounds from the soil surface. By referring to the organic matter rates of $3.81 \%$ for Dian and $6.03 \%$ for Moursi higher than Danga $1.90 \%$, one could thus explain the behavior of these two types of soils with regard to glyphosate.

By referring to the CEC of the different clays also, the same adsorption tendency is respected. Indeed, Moursi and Dian with a CEC of 36.6 and 27.2 adsorb more glyphosate than Danga with 19.6. Some studies have shown that the dominant mechanisms of glyphosate adsorption by montmorillonite are the complexation of exchangeable cations by water bridges or by cation exchanges [18]; [19]; [20].

Referring to the type of clay, the swelling clay rate is important for Moursi $56.7 \%$, Dian $30.6 \%$ and Danga $15.7 \%$. This could explain the order of adsorption of glyphosate on these clays.

Our results corroborate with those of Glass, 1987 [21] and Hill, 2001 [22] which showed that in glyphosate adsorption studies on soils, the clay rate, clay type or CEC are important factors.

These results are also in agreement with those of Kamate and Appleby (1987) [23] or Jonge and De Jonge (1999) [24] who also show that the increase in soil $\mathrm{pH}$ causes a strong reduction in the adsorption of glyphosate. Indeed, $\mathrm{pH}$ measurements carried out gave the following values: $\mathrm{Dian} \mathrm{pH}=$ 6.5; Moursi $\mathrm{pH}=7.5$ and Danga $\mathrm{pH}=8$. Adsorption therefore seems to evolve according to $\mathrm{pH}$. (See Table 2).

\section{Modeling by the Freundlich model}

This is an equation that is often used in the practical representation of the adsorption equilibrium between the solute and the clay surface. It is presented in the form $Q=K_{F} . \mathrm{Ce}^{1 / n}$

The scaling linearization of Freundlich relation leads to the following equation:

$$
\ln \mathrm{Q}=\ln \mathrm{K}_{\mathrm{F}}+1 / \mathrm{n} \ln \mathrm{Ce}
$$

This is the equation of a straight line of slope $1 / \mathrm{n}$ and intercept at origin $\log \mathrm{K}_{\mathrm{F}}$

Table3. Adsorption of glyphosate on soils according to Freundlich model

\begin{tabular}{|l|l|l|l|}
\hline & \multicolumn{3}{|c|}{ FREUNDLICH } \\
\hline & $\mathrm{KF}(L \cdot g-1)$ & $1 / \mathrm{n}$ & $\mathrm{R}^{2}$ \\
\hline Glypho Danga & 0,01 & 0,94 & 0,92 \\
\hline Glypho Dian & 4,33 & 2,74 & 0,89 \\
\hline Glypho Moursi & 0,20 & 0,20 & 0,95 \\
\hline
\end{tabular}

Table 3 shows the linearization results obtained using the Freundlich equation for glyphosate adsorption on the three types of clay soil. 
Thus, the kf values of adsorption isotherm according to Freundlich model range from 0.01 to 4.33 and the observed soil sorption gradient follows the order: Dian > Moursi >Danga;

The highest glyphosate $\mathrm{kf}$ value for the three clay soils is observed in the Dian soil which has a large specific surface area. The high organic matter content of the Moursi and Dian samples could explain the adsorption. The same is true for the relatively high percentages of clay in these soils.

In addition to soil type, adsorption could be explained by the solubility of the pesticide in water. Indeed, glyphosate has a solubility of $10.5 \mathrm{~g} / \mathrm{L}$, which gives it an affinity for the liquid phase and explains the low Kf values.

The results obtained showed different soil retention capacities. It turns out that the Moursi and Dian soils show a strong and rapid adsorption for this pesticide; however, this is not the case for Danga.

\section{CONCLUSION}

The characterization of clay soils showed three types of soils: silty for Moursi, silty-sandy for Danga and sandy-silty for Dian.

These three soil types contain quartz, feldspath and clay minerals which are kaolinite, montmorillonite and illite.

The specific surface areas are respectively $61.48 \mathrm{~m}^{2} / \mathrm{g}$ for Danga, $98.78 \mathrm{~m}^{2} / \mathrm{g}$ for Dian and $97.15 \mathrm{~m}^{2} / \mathrm{g}$ for Moursi and CECs ranging from 1.67 for Moursi, 1.86 for Danga and 2.95 for Dian.

Adsorption experiments show that glyphosate is better adsorbed on the soils studied because of their differences in solubility on the one hand and their respective structures on the other hand. When in contact with soil and clay minerals, glyphosate is immobilized due to the formation of surface complexes with metal ions, mainly $\mathrm{Fe}^{3+}, \mathrm{Al}^{3+}$ et $\mathrm{Ca}^{2+}[8]$ (Franz et al, 1997).

Adsorption of glyphosate depends on soil $\mathrm{pH}$; the increase in $\mathrm{pH}$ causes a strong reduction in adsorption, in agreement with Kawate and Appleby (1987) [23], Jonge and De Jonge (1999) [24].

From modelling also, it appears that the Moursi and Dian soils show strong and rapid adsorption for this pesticide; however, this is not the case for Danga. The relatively high organic matter and clay content of these soils may account for this adsorption.

A priori, the differences in solubility of glyphosate are large enough to induce differences in the amounts adsorbed.

\section{BIBLIOGRAPHY}

[1] http://malijet.com/la_societe_malienne_aujourdhui/evenements_agenda_au_mali/11890-pesticides_dans_1 agriculture.html.

[2]Gastaldi D., Ostacoli G., Torazzo A., Zelano V., (1998), Annali di chimica, 88, 657-665.

[3] Coulibaly, A., Derlon, J.-P. (1994): Pollution des eaux du Fleuve Banifing par les intrants agricoles chimiques: principaux résultats. Compagnie Malienne pour le Développement des Textiles, Bamako.

[4] Berthé, S.D, 2007. Pesticide Residus in soil and water from four cotton growing areas of Mali, West Africa. Agriculture, Food and Envir Sciences, vol 1. p 1934- 1935.

[5] (http://www.thenrgroup.net/theme/PAN-ecotox/pdf/annex_7_mali_mini-project_report.pdf)

[6] Omar Ben Khatab N'diaye (2010).Technologie de décontamination des sols contaminés par des pesticides au MALI.P22-P35

[7] Bélières, J. F., Barret, L., Sama, Z. C., Kuper, M. (2007). Organisation et rôle de la profession agricole dans le développement des systèmes irrigués - quelques enseignements tirés du cas de l'Office du Niger au Mali.

[8] Armand J. et Jacobsen O.S.(2001).Sorption and degradation of glyphosate and dichlobenil in fractured clay. BCPC Symposium Proceedings n ${ }^{\circ}$ 78: Pesticide Behaviour in soil and water-205-210.

[9] Jouenne C. A(1990)., "Traité de céramiques et matériaux minéraux", Editions Septima, pp.219 et 507, Paris.

[10] Morel, J. L.,(1996) Surface spécifique et capacité d'échanges cationiques (C.E.C) de quelques minéraux argileux. 
[11] Errais E., Duplay J., Darragi F(2010). Textile dye removal by natural clay- the case study of Fouchana Tunisian clay. Environnemental Technology, Vol 31, Issue 4, pp 373-380.

[12] Toraishi et al. 2002, Adsorption behavior of $\mathrm{IO}_{3}{ }^{-}$by $\mathrm{CO}_{3}{ }^{2-}$ - and $\mathrm{NO}_{3}{ }^{-}$-hydrotalcite ; Applied Clay Science Vol 22, Issues 1-2, pp 17-23

[13] You y. Vance G.F et Zhao.H (2001).Selenium adsorption on $\mathrm{Mg}$-Al and $\mathrm{Zn}-\mathrm{Al}$ layered double.hydroxides.App.claySci, 20, PP.13-25

[14] Barja, B.C. (1999). Interacción Química del Herbicida Glifosato y Compuestos Relacionados con Fe(III). Facultad de Ciencias Exactas y Naturales, Universidad de Buenos Aires. PhD Dissertation.

[15] Barja, B.C., dos Santos Afonso, M.(2005). Aminomethylphosphonic acid and glyphosate adsorption onto goethite: a comparative study. Environ. Sci. Technol. 39, 585-592.

[16] Barja, B.C., dos Santos Afonso, M. (1998). An ATR-FTIR study of glyphosate and its Fe(III) complex in aqueous solution. Environ. Sci. Technol. 32, 3331-3335.

[17] Barja, B.C., Herszage, J., dos Santos Afonso, M.( 2001). Iron(III)-phosphonate complexes Polyhedron 20, 1821-1830.

[18] Shoval, S., Yariv, S., (1979). The interaction between roundup (glyphosate) and montmorillonite. Part 1. Infrared study of the sorption of glyphosate by montmorillonite. Clays Clay Miner. 27, 19-28.

[19] Glass, R. L (1987) “Adsorption of Glyphosate by Soils and Clay Minerals”. J. Agric. Food Chem., 35, 497-500.

[20]. McConnell, J.S., Hossner, L.R. (1989). X-ray diffraction and infrared spectroscopic studies of adsorbed glyphosate. J. Agric. Food Chem. 37, 555-560.

[21] Glass R. L., (1987) Adsorption of glyphosate by soils and clay minerals J. Agric. Food Chem. 35, $497-500$

[22] Hill, H.H.(2001). Competitive sorption between glyphosate and inorganic phosphate on clay minerals and low organic matter soils. J. Radioanal. Nucl. Chem. 249,385-390

[23] Kawate M. K. and Appleby A. P. (1987). Effect of soil pH on Availability of Glyphosate in soil to Germinating Ryegrass Seedling. Journal of applied seed production, Vol. 5, 45-49.

[24] De Jonge H. and De Jonge L. W.(1999). Influence of $\mathrm{pH}$ and solution composition on the sorption of glyphosate and prochloraz to a sandy loam soil. Chemosphere, vol. 39, (5), 753-763.

Citation: B. Traoré,et.al.,, "Soil Type Influence on the Adsorption of Glyphosate in the "Office Du Niger" Zone in Mali " International Journal of Research Studies in Agricultural Sciences (IJRSAS), 2020; 6(9), pp. 613, https://doi.org/10.20431/2454-6224.0609002

Copyright: (C) 2020 Authors. This is an open-access article distributed under the terms of the Creative Commons Attribution License, which permits unrestricted use, distribution, and reproduction in any medium, provided the original author and source are credited. 